\title{
Curvature Effect on the Barrier from the Physisorption to the Chemisorption of $\mathbf{H}_{2}$ on Graphene
}

\author{
Baotao Kang, Sunwoo Kang, Shihai Yan, ${ }^{\dagger, *}$ and Jin Yong Lee* \\ Department of Chemistry, Sungkyunkwan University, Suwon 440-746, Korea. E-mail: jinylee@skku.edu \\ Qingdao Institute of Bioenergy and Bioprocess Technology, Chinese Academy of Sciences, Qingdao, 266101, China \\ Received October 8, 2010, Accepted January 13, 2011
}

\begin{abstract}
The curvature dependence of the physisorptions of $\mathrm{H}_{2}$ on graphene surface and their barrier to the chemisorptions has been studied. The graphene with steeper curvature can adsorb $\mathrm{H}_{2}$ stronger due to the more $s p^{3}$ character of the carbon. However, for the negative curvature, the binding strength of the physisorption and the barrier to the chemisorptions are determined by steric repulsion as well as the $s p^{3}$ character.
\end{abstract}

Key Words : Graphene, Hydrogenation, Adsorption, Curvature effect

\section{Introduction}

Graphene, a rising star in material science and condensed-matter physics, exhibits exceptionally high crystal and electronic quality that originate from its genuine atomic thickness. ${ }^{1}$ Recently, graphene has been extensively explored for hydrogen storage in hydrogen-fuel technologies because of its reversibility, stability, low weight, low toxicity, large surface area, and high hydrogen density. ${ }^{2} \mathrm{H}_{2}$ physisorption on graphene (around $3 \AA$ from the surface) is crucial to explain the experimental estimations for $\mathrm{H}_{2}$ storage in the carbon-based nanomaterials. ${ }^{3}$ Atomic hydrogenation of graphene, $\mathrm{H}_{2}$ chemisorption $(\sim 1.5 \AA)$, creates graphane at local, as it alters the hybridization of carbon atoms from $s p^{2}$ to $s p^{3}$, removing the conducting $\pi$-bands and opening an energy gap. ${ }^{4}$ The barrier between the physisorption and the chemisorption depends on the graphene curvature (Figure 1). ${ }^{5}$

As a matter of fact, several experimental observations concluded that at the ripple of the graphene the hydrogen can be better adsorbed due to the more $s p^{3}$ character hence

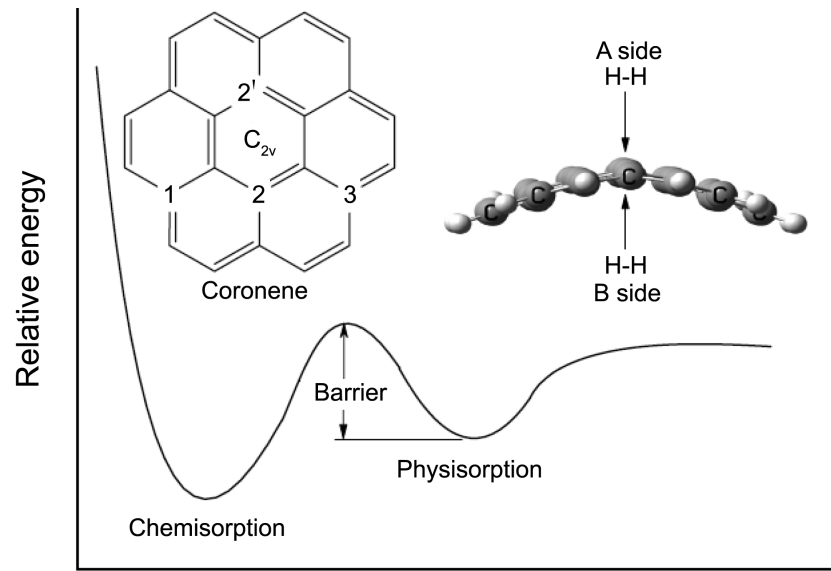

Reaction coordinate

Figure 1. Potential energy surface for hollow-site (2-2') dissociative adsorption of $\mathrm{H}_{2}$ on graphene. easier hydrogen adsorption. For example, the curvature of CNTs strongly influences both the barrier for sticking and the binding energy of chemisorbed hydrogen. Although the significance of the curvature effect has been recognized with the exploration on carbon nanotube, ${ }^{6}$ no such a systematic investigation on graphene. Here, we address these pendent problems with reliable $a b$ initio method.

\section{Calculation Methods}

Based on the chemical reaction theories, collision theory and activated complex theory, the collision frequency and the reaction barrier are the key parameters for reactivity. The collision frequency is assumed to be almost equivalent for the hydrogen adsorption on grapheme with different curvature. Thus, the reaction barrier from the physisorption to the chemisorption could give a direct evidence for the reactivity of graphene. Coronene is employed as the prototype model for graphene to explore the curvature effect on the barrier from the physisorption to the chemisorption on graphene (Figure 1). According to $\mathrm{C}_{1} \mathrm{C}_{2} \mathrm{C}_{3}$ angle, various curvature systems as well as the planar graphene are designed. The hollow-site (2-2') dissociative adsorptions of $\mathrm{H}_{2}$ on both positive (A side) and negative ( $\mathbf{B}$ side) sides in various curvatures are considered. The physisorption position is determined through the potential energy scan of the distance between the center of mass of $\mathrm{H}_{2}$ and graphene $\left(\mathrm{R}_{\mathrm{M}}\right)$. Then, all the transition states (TSs) for the given curvature systems were obtained to have an insight on the curvature effect of the reaction barrier between the physisorption and the chemisorptions. All the calculations were carried out at MP2/6-31G(d) level using a suite of Gaussian 03 programs. $^{7}$ The coronene was selected as a model system of the grapheme which is infinite 2-dimensional system with high symmetry, thus the $\mathrm{H} 2$ adsorption can be considered as $\mathrm{C}_{2 \mathrm{v}}$ regardless of the incident direction. Therefore, during calculations, all the geometries were fully optimized with the $\mathrm{C}_{2 \mathrm{~V}}$ symmetry constraint. In addition, the hydrogen is known to be dissociated at the surface of metal or other catalysts for 
Table 1. The $\mathrm{H}_{2}$ physisorption distance $\left(\mathrm{R}_{\text {ephys }}: \AA\right)$, physisorption binding energy $\left(\Delta \mathrm{E}_{\text {phys }}: \mathrm{kcal} / \mathrm{mol}\right)$, the $\mathrm{C} \cdots \mathrm{H}$ contact distance at the transition state $\left(\mathrm{R}_{\mathrm{C} \cdots \mathrm{H}}(\mathrm{TS}): \AA\right)$, and the barrier from the physisorption to the chemisorption $\left(\mathrm{E}_{\mathrm{barr}}: \mathrm{eV}\right)$ in various curvatures

\begin{tabular}{rlrrrrrrrrrrr}
\hline & $\angle \mathrm{C}_{1} \mathrm{C}_{2} \mathrm{C}_{3}$ & 98.5 & 106.7 & 115.2 & 124.4 & 135.4 & 144.2 & 147.1 & 150.1 & 156.1 & 164.3 & 180.0 \\
\hline \multirow{4}{*}{ A Side } & $\mathrm{R}_{\text {ephys }}$ & & 3.02 & 3.05 & 3.10 & 3.11 & 3.14 & 3.16 & 3.20 & 3.23 & 3.30 & 3.40 \\
& $\Delta \mathrm{E}_{\text {phys }}$ & & -0.42 & -0.42 & -0.42 & -0.41 & -0.37 & -0.37 & -0.36 & -0.34 & -0.32 & -0.31 \\
& $\mathrm{R}_{\mathrm{C} \cdots \mathrm{H}}(\mathrm{TS})$ & & 3.27 & 3.178 & 3.257 & 3.275 & 3.370 & 3.370 & 3.370 & 3.371 & 3.466 & 3.560 \\
& $\mathrm{E}_{\text {barr }}$ & & 1.477 & 2.116 & 2.892 & 3.728 & 4.706 & 5.033 & 5.298 & 5.837 & 6.557 & 7.954 \\
\hline \multirow{4}{*}{ B Side } & $\mathrm{R}_{\text {ephys }}$ & 5.20 & 4.50 & 3.90 & 3.64 & 3.58 & 3.55 & 3.52 & 3.50 & 3.49 & 3.43 & 3.40 \\
& $\Delta \mathrm{E}_{\text {phys }}$ & -0.18 & -0.28 & -0.46 & -0.56 & -0.48 & -0.41 & -0.39 & -0.38 & -0.35 & -0.33 & -0.31 \\
& $\mathrm{R}_{\mathrm{C} \cdots \mathrm{H}}(\mathrm{TS})$ & 5.302 & 4.619 & 4.038 & 3.736 & 3.751 & 3.656 & 3.656 & 3.656 & 3.657 & 3.561 & 3.560 \\
& $\mathrm{E}_{\text {barr }}$ & 5.203 & 4.862 & 4.683 & 4.538 & 4.510 & 4.641 & 4.768 & 4.769 & 5.066 & 6.003 & 7.954 \\
\hline
\end{tabular}

the catalytic hydrogenation process. Accordingly, we do not consider the head-on type adsorption in this study.

\section{Results and Discussion}

The potential energy surfaces (PESs) for the physisorption
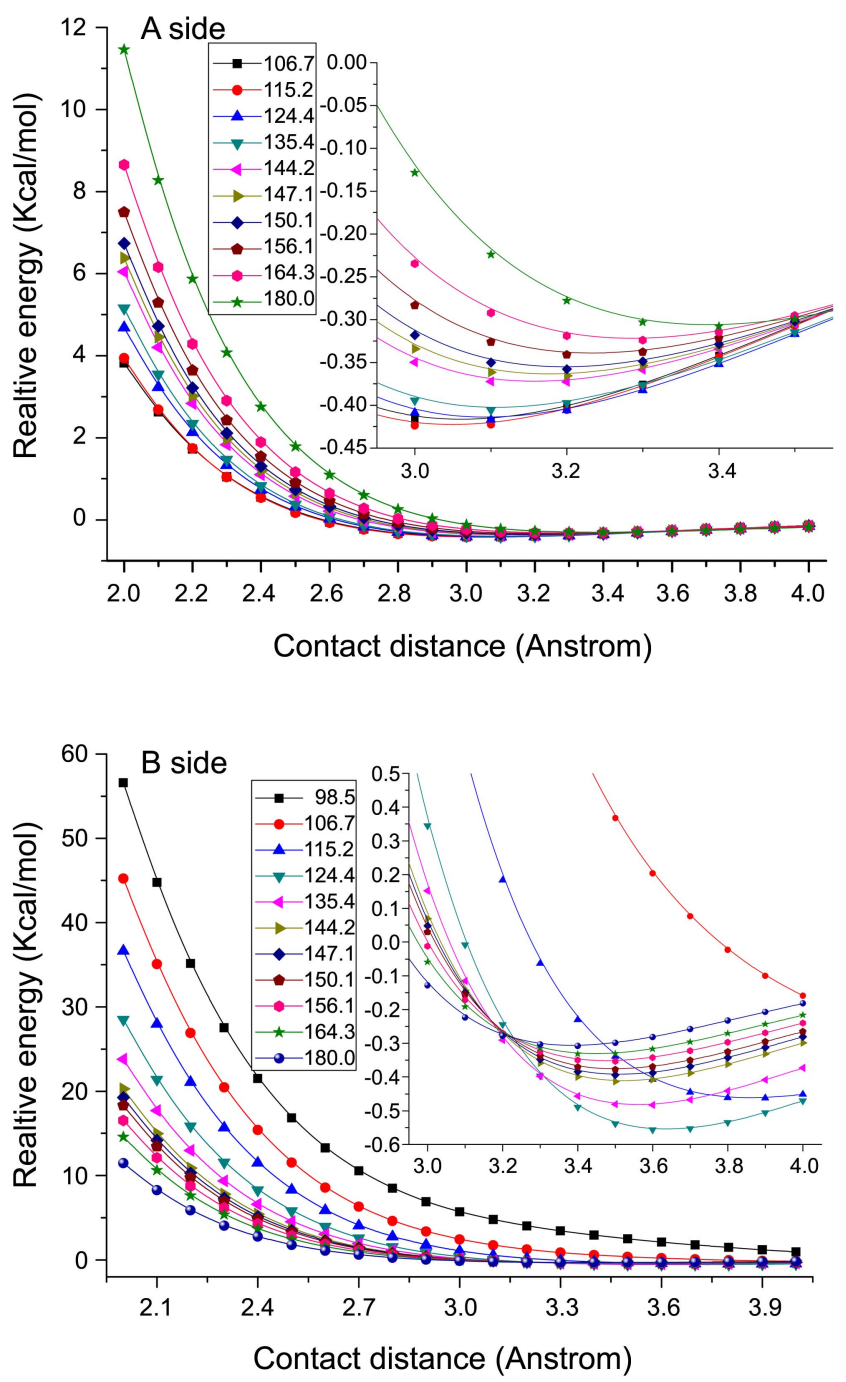

Figure 2. Potential energy surface of positive and negative curvatures according to the contact distance between the center of mass of $\mathrm{H}_{2}$ and coronene. at the $\mathrm{A}$ and $\mathrm{B}$ sides for various curvature systems scanned from 2 to $4 \AA$ of $\mathrm{R}_{\mathrm{M}}$ with the fragments $\left(\mathrm{H}_{2}\right.$ and coronene) geometries fixed to those of the isolated ones (Figure 2). Figure $2 \mathrm{a}$ shows that $\mathrm{H}_{2}$ can be adsorbed on $\mathrm{A}$ side by physisorption with the distances $\left(\mathrm{R}_{\text {ephys }}\right)$ at $3.0 \sim 3.4 \AA$. Furthermore, $\mathrm{R}_{\text {ephys }}$ decreases as the $\mathrm{C}_{1} \mathrm{C}_{2} \mathrm{C}_{3}$ angle decreases (i.e., steeper curvatures) with stronger binding as noted from Table 1. Our results are in good agreement with those observed in previous studies. ${ }^{5 a, 6 a}$ For the adsorption on $\mathbf{B}$ side, $\mathrm{R}_{\text {ephys }}$ tends to gradually increase, and as the $\mathrm{C}_{1} \mathrm{C}_{2} \mathrm{C}_{3}$ angle decreases in the range of $3.3 \sim 3.7 \AA$. However, the binding energy increases as the $\mathrm{C}_{1} \mathrm{C}_{2} \mathrm{C}_{3}$ angle decreases from 180.0 to 124.4 , reaches maximum, then decreases from 124.0 to 98.5 . This is because of the increased steric repulsion for the physisorption on $\mathbf{B}$ side in the very steep curvature. On the contrary, there is no such a repulsion for the physisorption on A side. Thus, the binding energy for physisorption is stronger as the $\mathrm{C}$ has more $s p^{3}$ character, and it competes with the steric repulsion on $\mathbf{B}$ side adsorption. The potential-wells of $\mathrm{H}_{2}$ physisorption should be deepened with the geometry optimizations, thus graphene should be a potential material for hydrogen storage.

$\mathrm{H}_{2}$ chemisorption has been expected to improve the hydrogen storage capacity of the carbon nanomaterial. ${ }^{8}$ In this connection, we studied the barrier $\left(\mathrm{E}_{\text {barr }}\right)$ from the physisorption to the chemisorption. The representative structures of the chemisorptions, physisorptions, and transition states for the $\mathrm{H}_{2}$ adsorption on coronene (both $\mathrm{A}$ and $\mathrm{B}$ side) for several curvatures $\left(\angle \mathrm{C}_{1} \mathrm{C}_{2} \mathrm{C}_{3}=180.0,150.1,124.4^{\circ}\right)$ were shown in Figure 3 . As seen in Figure 4 , the barrier on $\mathbf{A}$ side decreases linearly from 8.0 to $1.5 \mathrm{eV}$ as the $\mathrm{C}_{1} \mathrm{C}_{2} \mathrm{C}_{3}$ angle decreases, which is consistent with the previous report. ${ }^{6}$ This high barrier for the perfect planar geometry $\left(\angle \mathrm{C}_{1} \mathrm{C}_{2} \mathrm{C}_{3}=\right.$ 180.0 ) is due to the high stability of the physisorption state due to the resonance stabilization, and destabilization of the TS due to the loss of resonance stabilization energy. However, this high barrier might be somewhat decreased in the actual process because the dissociated hydrogen in the chemisorptions state may not have $\mathrm{C}_{2 \mathrm{v}}$ symmetry. Nevertheless, the barrier is mainly determined from the energy of the physisorption and the transition states, and we expect the calculated barrier may be reasonably acceptable with $\mathrm{C}_{2 \mathrm{v}}$ symmetry constraint. For the $\mathrm{C}_{1} \mathrm{C}_{2} \mathrm{C}_{3}$ angle of $\mathrm{ca}$. $125^{\circ}$, 


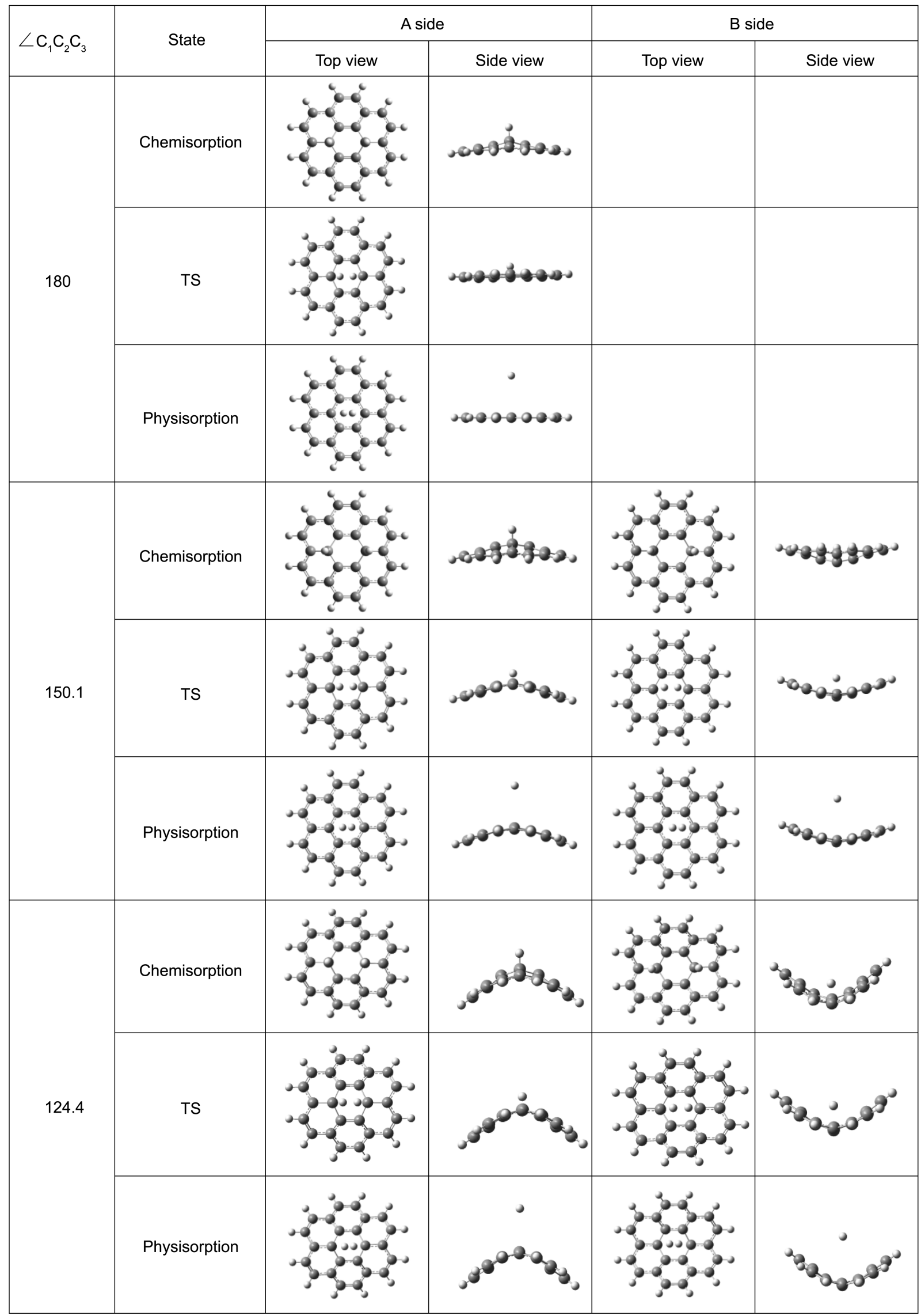

Figure 3. Calculated structures of the chemisorptions, physisorptions, and transition states for the $\mathrm{H}_{2}$ adsorption on coronene (both $\mathrm{A}$ and $\mathrm{B}$ side) with different curvatures $\left(\angle \mathrm{C}_{1} \mathrm{C}_{2} \mathrm{C}_{3}\right)$. 


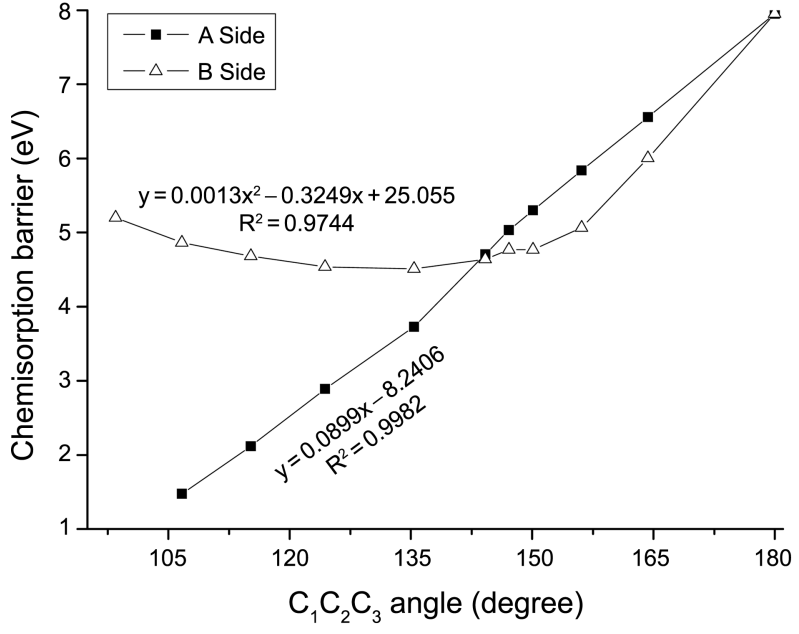

Figure 4. Barriers from the physisorption to the chemisorption. the barrier is $c a .3 \mathrm{eV}$, which is almost equal to that of $(5,5)$ single-wall nanotubes. ${ }^{6 \mathrm{~b}}$ The barrier depends on the hybridization variation of the carbon. The carbon has pure $s p^{2}$ hybridization in planar graphene. The $\mathrm{H}_{2}$ chemisorption on $s p^{2}$ carbon induces a change of the hybridization from $s p^{2}$ to $s p^{3}$ (even not perfect $s p^{3}$ ). In the case of steeper curvature, the carbon has more $s p^{3}$ character, thus it needs less change of the hybridization in changing into chemisorption, hence less barrier. For B side, the barrier changes non-linearly, quadratically. The barrier decreases initially with the curvature due to the enhanced $s p^{3}$ character in graphene carbon, then the lowest barrier $(4.5 \mathrm{eV})$ is obtained at $c a .130^{\circ}$ of $\mathrm{C}_{1} \mathrm{C}_{2} \mathrm{C}_{3}$ angle. For the steeper curvature than $130^{\circ}$, the barrier increases due to the increased steric repulsion as in the case of binding energy for the physisorption. This feature of the barrier dependence on the curvature for $\mathbf{A}$ and $\mathbf{B}$ sides can be explained by the highest occupied molecular orbitals

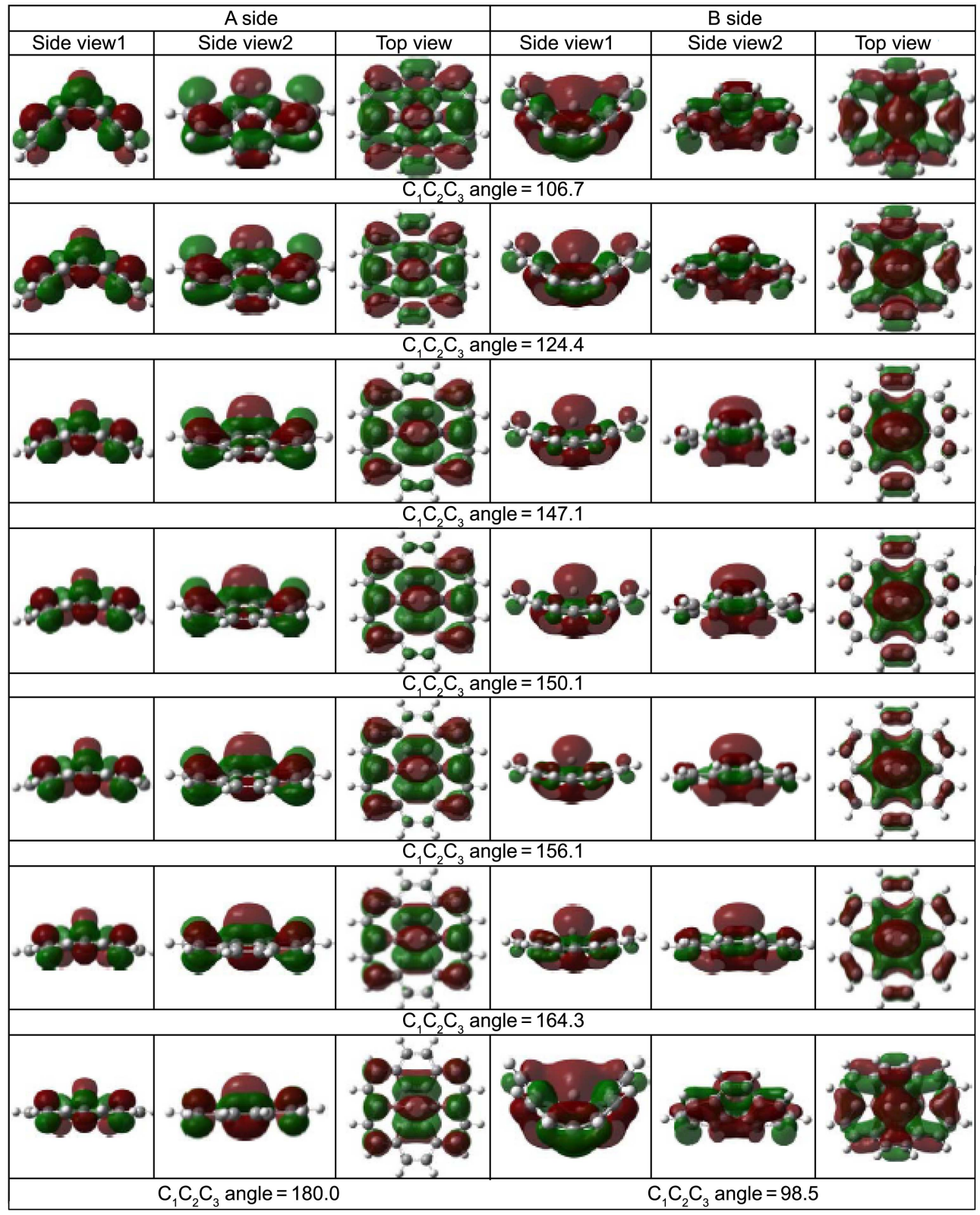

Figure 5. The highest occupied molecular orbitals (HOMOs) of various curvature systems. 
(HOMOs) (Figure 5). For the adsorption on $\mathbf{A}$ sides, the HOMOs are almost equivalent, while on $\mathbf{B}$ sides, they show significant changes.

\section{Conclusion}

In conclusion, the potential energy surfaces for $\mathrm{H}_{2}$ physisorption on curved graphenes and the barrier to the chemisorptions were investigated. The graphene with steeper curvature can adsorb $\mathrm{H}_{2}$ stronger due to the more $s p^{3}$ character of the carbon. However, for the negative curvature, the binding strength of the physisorption and the barrier to the chemisorptions are determined by steric repulsion as well as the $s p^{3}$ character. The graphene could be a potential material for catalytic hydrogenations if the curvature is appropriately controlled.

Acknowledgments. This work was supported by the National Research Foundation (NRF) grants funded by the Korea Government (MEST) (2010-0001630) and (20100000166).

\section{References}

1. (a) Geim, A. K.; Novoselov, K. S. Nat. Mater. 2007, 6, 183. (b) Elias, D. C.; Nair, R. R.; Mohiuddin, M. G.; Blake, S. V.; Morozov, P.; Halsall, M. P.; Ferrari, A. C.; Boukhvalov, D. W.; Geim, M. I.; Katsnelson, A. K.; Novoselov, K. S. Science 2009,
323,610 .

2. (a) Schlapbach, L.; Züttel, A. Nature 2001, 414, 353. (b) Yu, D.; Liu, F. Nano Lett. 2007, 7, 3046. (c) Ryu, S.; Han, M. Y.; Maultzsch, J.; Heinz, T. F.; Kim, P.; Steigerwald, M. L.; Brus, L. E. Nano Lett. 2008, 8, 4597. (d) A. Savchenko, Science 2009, 323 , 589 .

3. (a) Ghio, E.; Mattera, L.; Salvo, C.; Tommasini, F.; Valbusa, U. J. Chem. Phys. 1980, 73, 556. (b) Jeloaica, L.; Sidis, V. Chem. Phys. Lett. 1999, 300, 157. (c) Chang, H.; Pez, G. P.; Cooper, A. C. J. Am. Chem. Soc. 2001, 123, 5845. (d) Sha, X.; Jackson, B. Surf. Sci. 2002, 496, 318. (e) Zecho, T.; Güttler, A.; Küppers, J. Carbon 2004, 42,609

4. (a) Zecho, T.; Güttler, A.; Sha, X.; Jackson, B.; Küppers, J. J. Chem. Phys. 2002, 117, 8486. (b) Miura, Y.; Kasai, H.; Dino, W.; Nakanishi, H.; Sugimoto, T. J. Appl. Phys. 2003, 93, 3395. (c) Hornekær, L.; Šljivančanin, Z.; Xu, W.; Otero, R.; Rauls, E.; Stensgaard, I.; Lægsgaard, E.; Hammer, B.; Besenbacher, F. Phys. Rev. Lett. 2006, 96, 156104. (d) Sofo, J. O.; Chaudhari, A. S.; Barber, G. D. Phys. Rev. B 2007, 75, 153401. (e) Boukhvalov, D. W.; Katsnelson, M. I.; Lichtenstein, A. I. Phys. Rev. B 2008, 77, 035427.

5. (a) Okamoto, Y.; Miyamoto, Y. J. Phys. Chem. B 2001, 105, 3470. (b) Chernozatonskii, L. A.; Sorokin, P. B.; Brüning, J. W. Appl. Phys. Lett. 2007, 91, 183103.

6. (a) Tada, K.; Furuya, S.; Watanabe, K. Phys. Rev. B 2001, 63, 155405. (b) Lee, E.-C.; Kim, Y.-S.; Jin, Y.-G.; Chang, K. J. Phys. Rev. B 2002, 66, 073415. (c) Ruffieux, P.; Gröning, O.; Bielmann, M.; Mauron, P.; Schlapbach, L.; Gröning, P. Phys. Rev. B 2002, 66, 245416.

7. Frisch, M. J. et al. Gaussian 03, Gaussian, Inc., Wallingford, CT, 2004

8. Zhou, B.; Guo, W.; Dai, Y. J. Phys. Chem. C 2008, 112, 18516. 